\title{
Cell Interactions Underlying Purkinje Cell Replacement by Neural Grafting in the pcd Mutant Cerebellum
}

\author{
Constantino Sotelo
}

\begin{abstract}
The results obtained with neuronal grafting in an animal model of heredo-degenerative ataxia (the pcd mutant mouse) have been extremely useful to unmask new aspects of neural plasticity. The grafted embryonic Purkinje cells invade the deficient molecular layer of the host by migrating radially through adult Bergmann fibers. There, they start building their dendritic trees and, by promoting the axonal sprouting of specific adult neuronal population in a timed sequence, they receive appropriate synaptic contacts, starting ten days after grafting. Twenty-one days after grafting, the grafted Purkinje cells have acquired their adult dendritic pattern and synaptic investment. Both the detailed timetable and the nature of the cellular interactions between embryonic and adult neural cells are remarkably similar to those occurring during normal development. These results raise the possibility that embryonic Purkinje cells can induce in adult neural cells a new type of plasticity, that of recreating a permissive microenvironment for the synaptic integration of the grafted neurons, leading to the anatomical restoration of the cortical circuit of the mutant cerebellum.

RÉSUMÉ: Interactions cellulaires qui sous-tendent le remplacement, par greffe neurale, des cellules de Purkinje dans le cervelet de la souris mutante pcd. Les résultats obtenus par greffe neurale dans un modèle animal d'ataxie hérédo-dégénérative (la souris mutante pcd) ont permis de dévoiler des aspects nouveaux de la plasticité neurale. Les cellules de Purkinje embryonnaires greffées envahissent la couche moléculaire de l'hôte en migrant radialement sur les fibres de Bergmann adultes. Dans cette couche, les neurones greffés commencent à bâtir leurs arbres dendritiques et, en provoquant la poussée collatérale des axones de populations neuronales spécifiques de l'hôte, ils vont recevoir des contacts synaptiques appropriés, à partir de 10 jours après transplantation. Vingt et un jours après transplantation, les cellules de Purkinje greffées ont déjà acquis des arbres dendritiques et une synaptologie de type adulte. La chronologie et la nature des interactions entre cellules neurales embryonnaires et adultes sont remarquablement similaires à celles qui ont lieu pendant le développement normal. Ces résultats incitent à penser que les cellules de Purkinje embryonnaires peuvent induire dans les cellules neurales adulte un type nouveau de placticité : la recréation d'un microenvironnement permissif pour l'intégration synaptique des neurones greffés, entraînant la restauration anatomique d'un circuit cortical de la souris mutante.
\end{abstract}

Can. J. Neurol. Sci. 1993; 20 (Suppl. 3): S43-S52

Experimental neuronal transplantation has made important advances in recent years. ' The lack of successful therapy to improve the irreversible functional impairments consecutive to massive neuronal cell death in neurodegenerative diseases has prompted some clinicians to use neuronal grafts as a palliative treatment. Such trials have culminated in the first apparently successful treatment of a patient with Parkinson's disease, who was implanted with human embryonic, ventral mesencephalic cells. ${ }^{2}$ Independently of the controversies raised about this surgical approach, it must be stated that Parkinson's disease offers the optimal theoretical conditions for human application of neural grafting. Indeed, the major histopathologic problem in the disease is the progressive degeneration of dopaminergic nigral neurons and their projections to the basal ganglia. This dopaminergic projection constitutes a modulatory system of the type we have called a "diffuse or global system". "It is characterized by the fact that relatively few neurons innervate a large population of target nerve cells bearing specific receptors, and that the issuing neuronal communication is mostly of the paracrine type. Thus, the presence of metabolically active dopaminergic neurons implanted within their terminal domains in the basal ganglia might replace the defective dopaminergic projection of the parkinsonian patient.

The situation is entirely different with systems that are organized in a "point-to-point" manner, such as the cerebellum. The cerebellar function is based on the highly specialized architectural relationship of the neurons, that is to say on the axonal wiring and the consequent synaptic specificity. The cellular 


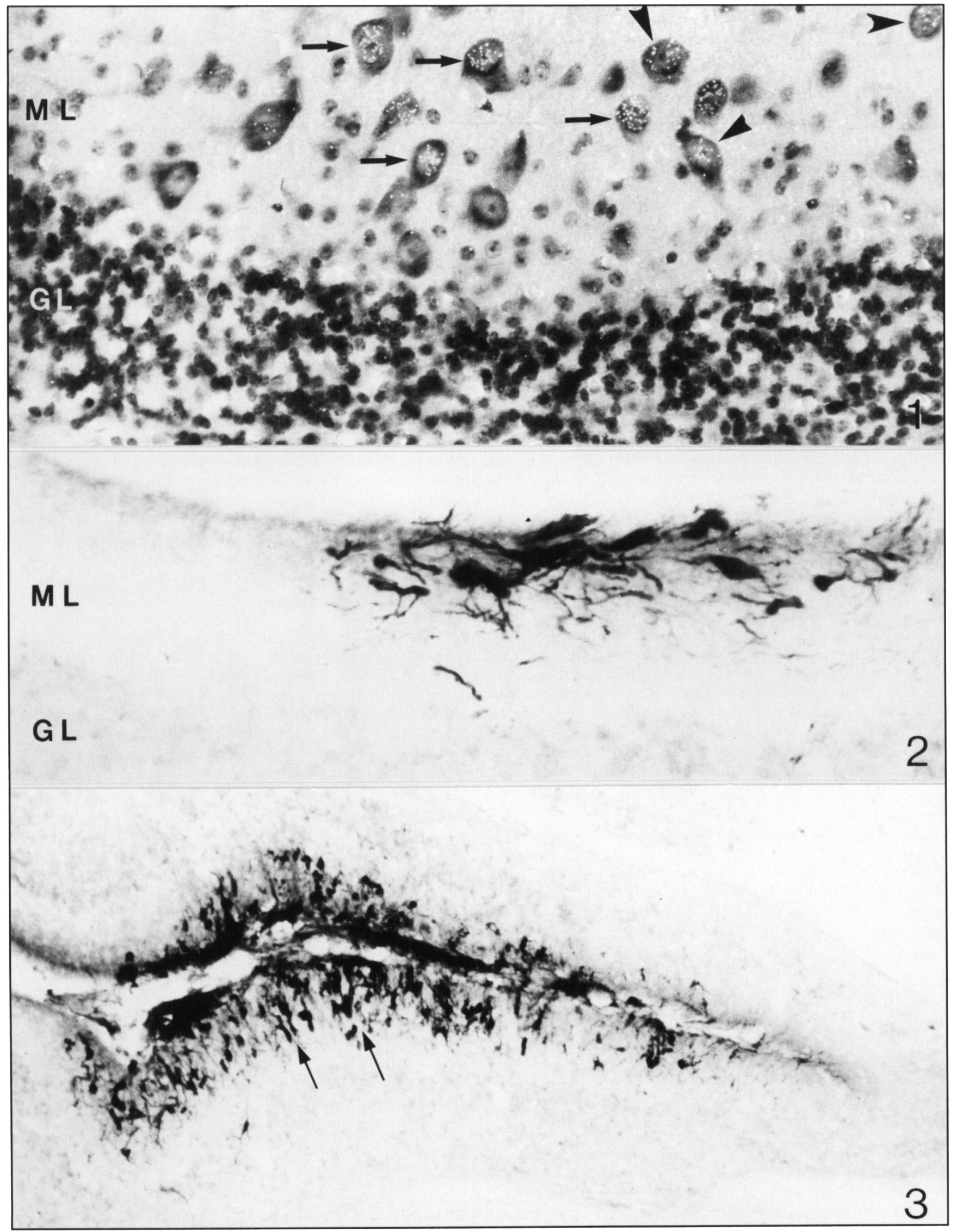


Figure I - Autoradiogram of a paraffin section stained with cresyl violet. This sagittal section passes through a folium of the cerebellum of a ped mouse injected with tritiated thymidine 6 and $24 \mathrm{~h}$ after transplantation, and fixed 60 days later. The interface between the molecular (ML) and the granule cell layer is deprived of host Purkinje cells. Grafted Purkinje cells spread throughout the superficial four-fifths of the ML. Note that the majority of these neurons have nuclei labeled with silver grains (white points in this bright and dark field micrograph). In some of the nuclei the number of silver grains is very high (arrows), whereas in others (arrowheads) they are less numerous. $\times 500$

Figure $2-C a B P$ immunostained section through the molecular layer $(M L)$ of a folium of a pcd cerebellum 5 days after grafting. Note the presence of grafted CaBP positive Purkinje cells with bipolar shapes, CaBP positive, at the surface of the folium forming the tangential migratory stream. Sagittal section. $\times 350$

Figure $3-\mathrm{CaBP}$ inmunostained section through two adjacent folia of a pcd cerebellum 7 days after grafting. Note that the grafted CaBP positive Purkinje cells have changed polarity, being now radially disposed in the host molecular layer (arrow's). Sagittal section. $\times 70$

replacement of missing Purkinje cells - the target neurons in numerous heredo-degenerative ataxias - by neural grafting raises much more complex problems than the replacement of modulatory nigral dopaminergic neurons in Parkinson's disease. This replacement is only effective when the grafted PCs become synaptically integrated into the host cerebellar circuit, reconstituting the anatomical integrity of the damaged networks. We have achieved some success in cerebellar grafting using mutant mice with affected cerebellum..$^{3-7}$ However, the synaptic integration of the implanted PCs is, in most instances, only partial. Thus, human trials such as those recently published ${ }^{8}$ seem, at least, premature.

\section{The pcd Mouse: Animal Model of Familial Cerebellar Cortical Atrophy}

"Purkinje cell degeneration" (pcd) is an autosomal recessive mutation, mapped on chromosome 13, that arose spontaneously in the C57BL/cdJ mouse strain. ${ }^{9}$ In the homozygous mice, the cerebellum develops normally, but when the animals reach the age of 15 to 18 days there is a process of rapid degeneration of the $\mathrm{PCs}^{10}$ that leads to the almost complete death of this neural population by $\mathrm{P} 45$. In pcd mice aged 4 months, less than 120 PCs remain, most of them in the nodulus." The vulnerability of PCs to the gene effect is not the same for all these neurons, even if they do degenerate. Indeed, in mice aged between 25 and 30 days, there are PCs which still resist the effect of the mutation. The latter are not randomly distributed but are densely packed and arranged symmetrically in broad sagittal bands, revealing once more the heterogeneity of this neuronal population. ${ }^{12}$

In the pcd mouse, the death of PCs is accompanied by a transneuronal degeneration of neurons of the inferior olive. This degeneration starts very early, between P17 and P23, ${ }^{13}$ and in adult animals of the age used in our grafting experiments the cell deficit is about $30 \% .^{14}$ Granule cells are more resistant to transneuronal degeneration, and it is only between 3-6 months that they degenerate. ${ }^{15}$ Thus, pcd mice older than 60 days are more than $99 \%$ free of PCs with much of the remaining cerebellar architecture in place, providing an optimal model for human cerebellar atrophies. In fact, the mutant's histopathologic changes and their timetable are somewhat similar to those taking place in some familial cerebellar cortical atrophies, particularly in those of the Holmes' type. ${ }^{16}$ In the experiments reviewed in this paper, homozygous pcd mice aged of 60 to 120 days were used as hosts. Donor tissue was taken from the cerebella primordia of 12-day-old (E12) embryos and of the C57BL strain, and implanted as small solid masses of the embryonic tissue.

\section{Synaptic Integration of Grafted PCs: Results Obtained With Long-term Survivals}

As discussed above, neuronal replacement in the cerebellar point-to-point system requires that the grafted PCs fulfill three essential prerequisites for the reconstruction of an equivalent cerebellar circuit: ${ }^{3.4}$ 1) Neurons homotypic to the missing ones need to migrate out of the solid grafts into the depleted homotopic region of the host. Our results, using immunostaining of grafted PCs with selective markers (antibodies against calbindin (CaBP) or cyclic GMP-dependent protein kinase) have proven that there is specificity in the cellular sorting out and invasion of the host cerebellum. Indeed, one to three months after implantation, the vast majority of the grafted PCs have moved out the graft and occupy the host molecular layer. In the largest transplants, the diameter of this spread is of $1.4 \mathrm{~mm}$, indicating that the maximal distance covered by grafted PCs is $700 \mu \mathrm{m} .^{4.5}$ Moreover, this invasive behavior seems to be exclusively for the embryonic PCs, since the density of cerebellar cortical interneurons is not increased in the transplanted mice, 2) Once in the host molecular layer, the replacing neurons need to develop adequate dendrites and establish appropriate synaptic contacts with host efferent fibers. This prerequisite is also achieved, since despite the ectopia of the grafted PC somata, which take residence in the upper four-fifths of the molecular layer, these neurons have dendrites that fill the layer completely and that mimic most of the features of normal PC dendritic trees. Moreover, the grafted neurons receive qualitatively normal synaptic innervation from climbing and parallel fibers as well as from axons of molecular layer interneurons. ${ }^{3.4 .5}$ Electrophysiological studies reveal these host afferents to the grafted PCs to be functional. ${ }^{17} 3$ ) In their turn, the grafted PCs should reconstitute the disrupted corticonuclear projection. This third prerequisite has been more difficult to realize. With the exception of a few grafted mice, in which a small percentage of grafted PCs has been able to grow axons that have reached the host deep cerebellar nuclei through the white matter, and have established synapses with appropriate target neurons, the vast majority of these axons remain confined to the host molecular layer, being unable to cross the molecular/granular layer interface. Thus, although our results indicate that this prerequisite can occasionally be achieved, much more work is needed to provide to the growing axons of grafted PCs a permissive substratum for the re-establishment of a corticonuclear projection. ${ }^{6}$ Without the projection, indicative of the complete synaptic integration of the grafted PCs, the restoration of an improved cerebellar function is inconceivable. 


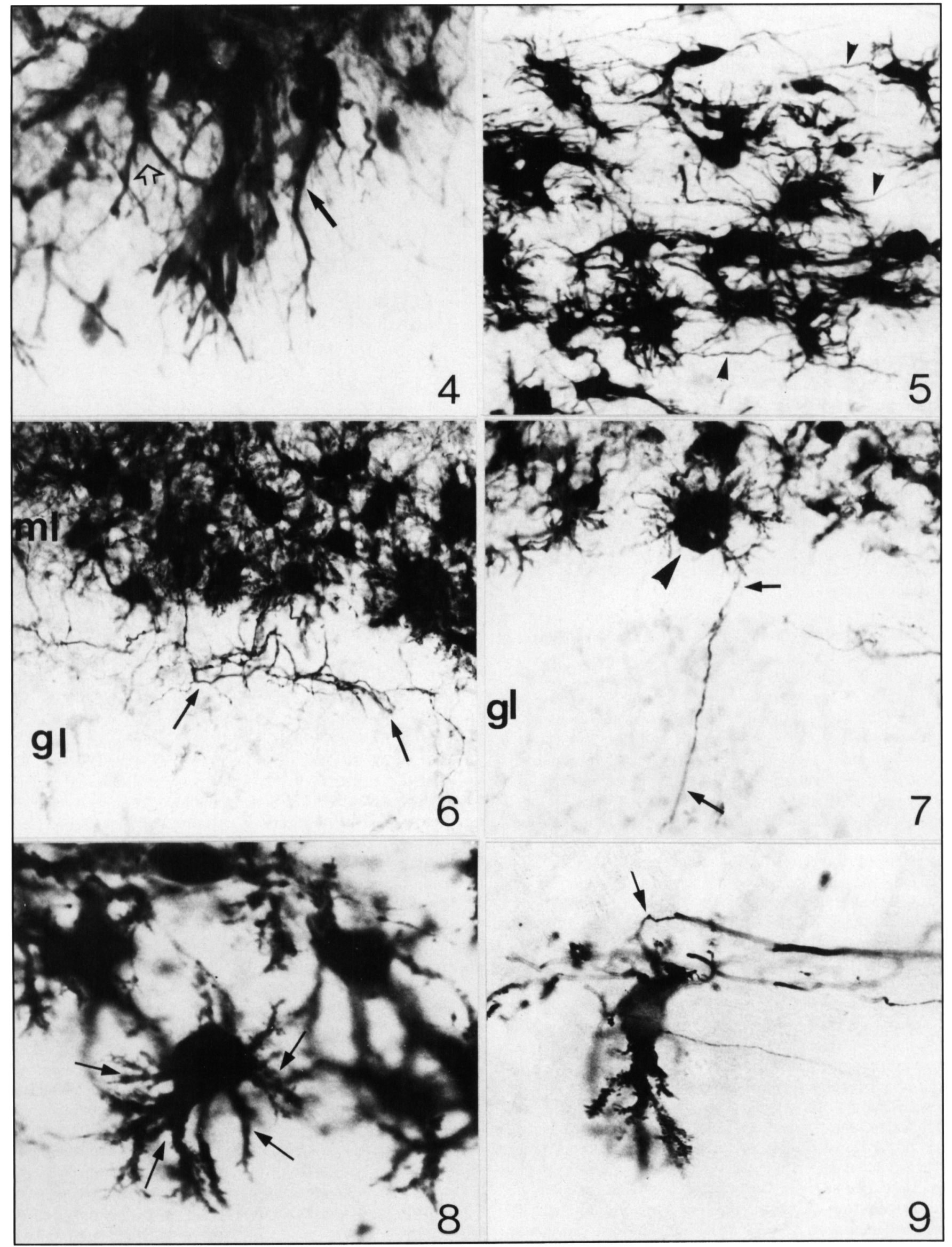


Figure 4-Grafted Purkinje cells, CaBP positive, 7 days after grafting. These neurons have finished their radial migration. They exhibit fusiform shapes either typical bipolar (arrow) or with a branched basal dendrite (open-arrow). Sagittal section. $\times 650$

Figure 5-Grafted Purkinje cells, CaBP positive, 10 days after grafting. These neurons, that appear now as "stellate cells", are scattered throughout the host molecular layer. Note that the axons remain within this laver (arrowheads). Frontal section. $\times 400$

Figure 6-Grafted Purkinje cells, CaBP positive. II days after grafting. The arrows point to hypertrophic aberrant plexuses formed by axons of the grafted neurons at the interface between the host molecular $(\mathrm{ml})$ and granule cell layer $(\mathrm{gl})$. Sagittal section. $\times 400$

Figure 7 - Grafted Purkinje cells, CaBP positive. Il days after grafting. These neurons are in the "stellate phase" of their dendritic developmem (arrowhead). The arrow's point to a CaBP positive aton that succeeds in crossing the host granule cell layer (gl). Sagittal section. $\times 400$

Figure 8-Grafted Purkinje cells, CaBP positive. 14 days after grafting. At this age the neurons have entered their third phase ("orientation and flattening") of their dendritic development. Those Purkinje cells, with perikarya lying at the middle of the host molecular laver, have developed multiple stem dendrites (arrows) that branch into secondary and distal segments. Sagittal section. $\times 650$

Figure 9-Grafted Purkinje cell. CaBP positive, 14 days after grafting. This superficial neuron, taken from the distal end of the migratory stream. has a relatively flattened, inverted dendritic tree. The axon emerges from the apical pole and bends (arrow') shortly after to run in the host molecular layer parallel to the pial surface. Frontal section. $\times 550$

\section{PC Replacement: Developmental Issues}

The results obtained in long-term survivals indicate that grafted PCs have reached a degree of maturation and a synaptic investment very similar to those of adult PCs in control cerebellum. Thus, despite the age mismatch, adult glial cells and neurons may become successful partners for the cell-to-cell interactions leading to the PC maturation. The aim of this review is to present evidence in favor of such embryonic/adult cellular interactions, and to discuss their nature to reach the conclusion that embryonic PCs are able to pursue their developmental history even when implanted in the adult pcd cerebellum.

The principal events in cerebellar development occur in sequential critical steps, from the cellular proliferation of stem cells in the cerebellar neuroepithelium to the functional validation and selective elimination of synaptic connections ${ }^{18}$ resulting in the formation of the cortical circuit of the cerebellum. In order to determine whether or not grafted PCs are able to recapitulate their developmental history within the adult host cerebellum, short-term survivals have been analyzed in a timed sequence from 3 up to 21 days after grafting (3-21 DAG), to compare at a given age the stage of maturation of the grafted PCs with that normally occurring in cerebellar ontogenesis. ${ }^{19-21}$

\section{Proliferation of Grafted PCs}

In control mouse embryos, $\mathrm{PCs}$ are generated in a short period of $72 \mathrm{~h}$ starting at E11.22 Hence, our solid transplants (taken from E12 embryos) contain less than $25 \%$ of postmitotic PCs and a large number of progenitors. In order to determine if the grafting conditions (traumatic dissection of the cerebellar primordia, change of local environment) could influence the proliferation period of these progenitors, a first series of grafted pcd mice received two intraperitoneal pulses of tritiated thymidine ( $5 \mu \mathrm{Ci} / \mathrm{g}$ b.wt.) 6 and 24 hours after grafting, a second series received the isotope 60 and 70 hours after grafting, and both were prepared for autoradiographic detection 45-60 DAG. ${ }^{20}$ Labeled PCs were only obtained in animals of the first series (Figure 1). In this case, the proportion of labeled nuclei among those PCs dispersed through the host molecular layer was greater than $50 \%$. Some of them were heavily labeled (arrows in
Figure 1), whereas some others contained fewer silver grains (arrowheads in Figure 1), indicating that some of the precursors have gone through at least two mitotic cycles. The absence of labeled PCs in mice of the second series strongly suggests that the grafted progenitors proliferate with a similar time window to that occurring during normal development.

\section{Migration of Grafted PCs}

About 4-5 DAG, when the solid implant is physically integrated within the host adult cerebellum, a migratory stream appears at the interface between the graft and the host. This stream emerges from the graft and moves off at the periphery of the folium, between the subpial surface and the glial limiting membrane. At its emergence the stream consists of a 5-7-celldeep layer, and at its end (about $700 \mu \mathrm{m}$ away) it is formed by a row of single elongated neurons. The time-course of this early tangential migration, and the absence of mitotic figures among the homogeneous cells forming the stream are valuable evidence that, as during normal development, only postmitotic PCs are able to migrate. The confirmation that the immature neurons were indeed postmitotic PCs was obtained with CaBP immunostaining, which revealed the presence of bipolar, immature neurons (Figure 2) very similar to migrating PCs in E18 normal mouse embryos.

Six to seven DAG, grafted PCs massively penetrated the host molecular layer (Figure 3), by changing polarity and adopting a bipolar radial or somewhat oblique position. The inward-oriented processes do not enter the granule cell layer, but stop abruptly at the molecular/granule cell layer interface. The radial position of these migrating PCs, and the ultrastructural observation ${ }^{19.20}$ of direct appositions between them and host Bergmann glial fibers, indicate that this neuronal migration takes place through the glial axis offered by the host Bergmann fibers.

Fifteen DAG, in regions of the host molecular layer containing the grafted PCs, the somata of the latter are still distributed in the superficial four-fifths of this layer (similar to what we have reported above in long-time survivals). This unchanged position confirms that the arrest of migration and perikaryal translocation is concurrent with the arrival of the inward-growing 


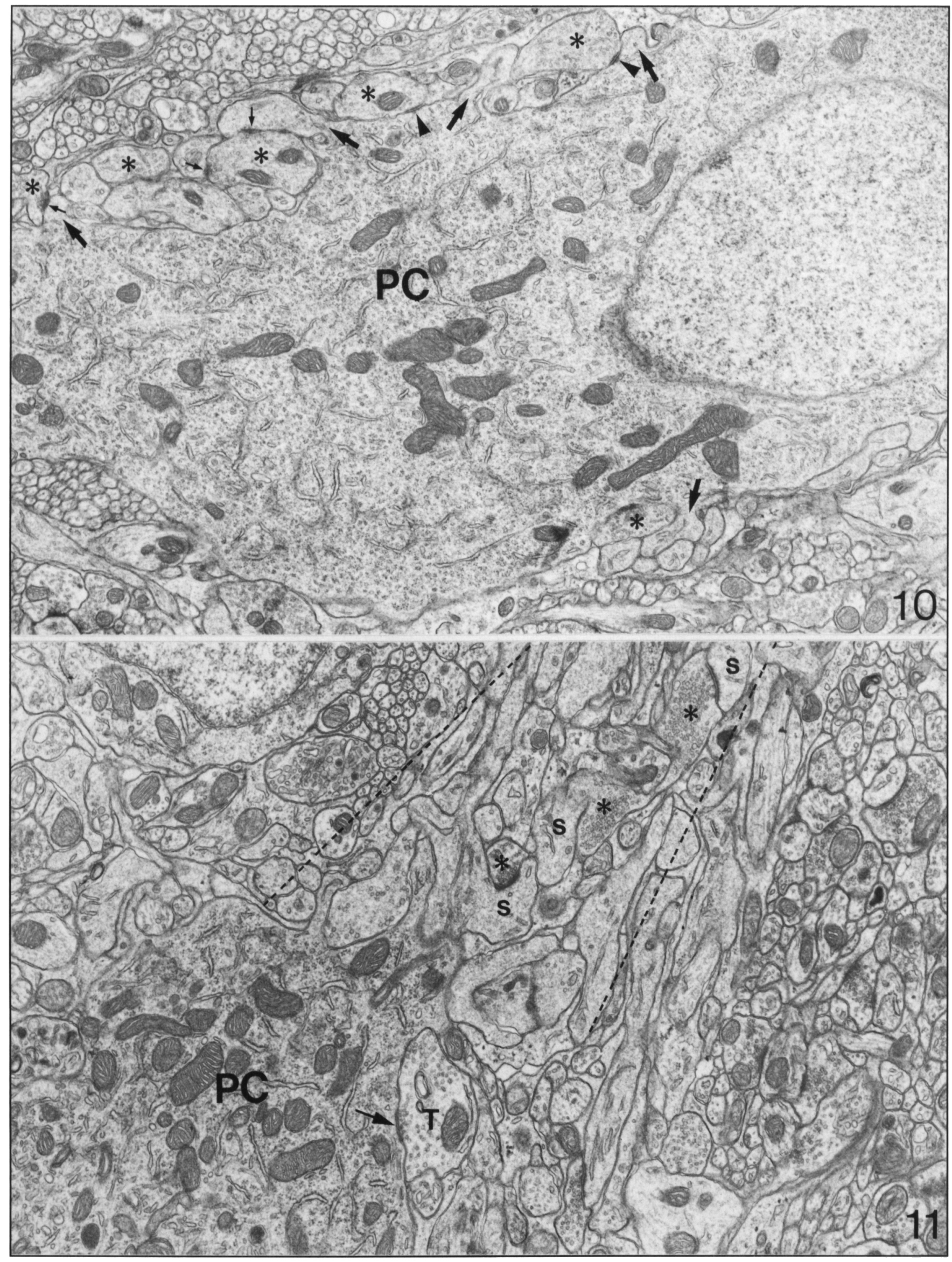


Figure 10-Electron micrograph of a grafted Purkinje cell ( $P C), 10$ days after grafting. Axonal sprouts (asterisks), orginated from host climbing fibers, cover part of the neuronal perikaryon. The large arrow's point to the emergence of somatic filopodia. Note ihe presence of attachment plates (arrowheads) and synaptic contacts (small arrow's) between the axonal sprouts and the grafted Purkinje cell. $\times 13.500$

Figure $1 /$ - Electron micrograph of a grafted Purkinje cell $(P C)$, II days after grafting. Host climbing fiber varicosities (asterisk) establish synaptic contacts on spines ( $s$ ) emerging from a tangentially cut stem dendrite (out of plane, outlined by the broken lines). The smooth surface of the perikaryon receives one symmetrical synapse (arrow) from an axon terminal (T) belonging to a host molecular layer internetron (basket or stellate cell). $\times 17,500$

processes at the upper limit of the granule cell layer, 7 DAG. Furthermore, these observations point to the fact that PC migration is arrested when the permissive microenvironment offered by the host Bergmann fibers abruptly stops at the interface between the molecular and the granule cell layer.

\section{Neuritic Differentiation of Grafted PCs}

At the end of their migration period, grafted PCs begin to develop the final form of their dendritic trees, following the same sequential phases described by Ramón y Cajal ${ }^{23}$ for the "in situ" maturation of these neurons. During their radial migration grafted PCs acquire a bipolar shape, similar to that of the "phase of the fusiform corpuscle" (Figure 4). They are characterized by an elongated cell body with asymmetrically long processes emerging from the opposite poles.

Ten to eleven DAG, the shape of these neurons has completely changed, owing to the retraction of the long and smooth dendrites and the appearance of numerous, long somatic filopodia (Figure 5), giving to the grafted PCs the features of these cells during the "phase of the stellate cell with disoriented dendrons" 23 (Figures 5, 6,7). This change in shape coincides with the beginning of the synaptogenesis with host climbing fibers (see below) and takes place when the grafted PCs reach the biological age of 2 to 3 postnatal days. The passage from this second to the third phase, that of "orientation and flattening of the dendritic trees", ${ }^{23}$ occurs faster than in normal development and in an asynchronic manner, since by 11 DAG a few grafted PCs have already reached this phase. It is, however, 14 to $15 \mathrm{DAG}$ that all these neurons are into the third phase of their dendritic maturation (Figures 8, 9). Most of the perikarya of ectopic PCs have developed multiple primary dendritic stems, profusely branching into secondary and distal segments (Figure 8). Some of them, particularly those with superfical cell bodies, develop dendrites down into the molecular layer, giving to these cells the appearance of inverted PCs (Figure 9). In both instances, the dendritic arbors are flattened in the sagittal plane, perpendicular to bundles of host parallel fibers.

Concomitantly with the maturation of the dendritic trees, the grafted PCs develop their axonic fields. Because of their inward migration, the axons emerge often from the apical pole of the bipolar migrating $\mathrm{PCs}$, and have the tendency to form loose bundles at the superficial region of the host molecular layer. When the grafted PCs reach the second and third phases of their dendritic maturation, the axons of those inverted PCs emerge from the apical pole and bend shortly after (Figure 9). The axons of multipolar PCs can emerge from different regions of the cell bodies (Figure 5 ). In any case, practically all these axons remain confined to the host molecular layer (Figure 5), in which they run for long distances in the frontal plane, together with bundles of host parallel fibers. In a few instances, some of the axons tend to penetrate the granule cell layer but are arrested at its interface with the molecular layer, where they form aberrant plexuses (Figure 6). Only very seldom, and for unknown reasons, a $\mathrm{CaBP}$ positive axon can cross the granule cell layer, reaching the white matter axis of the folium (Figure 7). Hence 14 DAG, the fate of the grafted PC axons is already committed, and remains unchanged in long-term survival. ${ }^{6}$

The confinement of the CaBP positive axons to the host molecular layer, together with the presence of the hypertrophic aberrant plexuses, strongly suggests that the molecular/granular cell layer interface is an impassable obstacle for grafted PC axons. Without finding a way to overcome this obstacle, the complete synaptic integration of the grafted PCs, leading to the restoration of the deficient pcd cerebellum, will not be achieved.

\section{Synaptogenesis of Grafted PCs}

The ultrastructural analysis of the synaptogenesis between grafted PCs and adult host axons has allowed us to conclude that this proceeds also according to a precise program, recapitulating all the stages described during normal ontogenesis. ${ }^{24.25}$

Ultimate synaptogenesis starts 10 to $11 \mathrm{DAG}$, when the grafted PCs enter the second phase of their dendritic development (biological age for PCs: 2 to 3 postnatal days). Host climbing fibers send axonal sprouts, of immature cytologic features, that establish synaptic contacts with emerging somatic filopodia (Figure 10), covering most of the basal pole of the PC soma. Thus, as during normal ontogeny, synapse formation between climbing fibers and PC somatic filopodia (the "pericellular nests") ${ }^{24}$ opens the synaptogenic period; from 12 to $14 \mathrm{DAG}$, synaptogenesis is very active and faster than during normal development. Climbing fiber translocation from perisomatic to peridendritic sites starts by 12 DAG (Figure 11), together with the establishment of somatic synaptic contacts by terminals of the basket and/or stellate axons (Figure 11). The translocation of the climbing fibers is a relatively slow process, and at $14 \mathrm{DAG}$ many grafted PCs still receive perisomatic climbing fiber inputs that remain at the proximity of synapses from axons of molecular layer interneurons (Figure 12). From 12 DAG, when most of the grafted PCs enter the third phase of their dendritic development, axonal varicosities of the host parallel fibers begin to establish synaptic contacts on newly-formed dendritic spines (Figure 13). By 14 DAG, this synaptogenesis proceeds at a very high rate (Figure 14), and the inputs are segregated into proximal and distal dendritic compartments. ${ }^{26}$ By 21 DAG, the synaptic investment of the grafted PCs is qualitatively similar to that reported in long-term survivals. ${ }^{4}$

Electrophysiological studies on the formation of synapses between climbing fibers and PCs in the postnatal rat cerebellum 


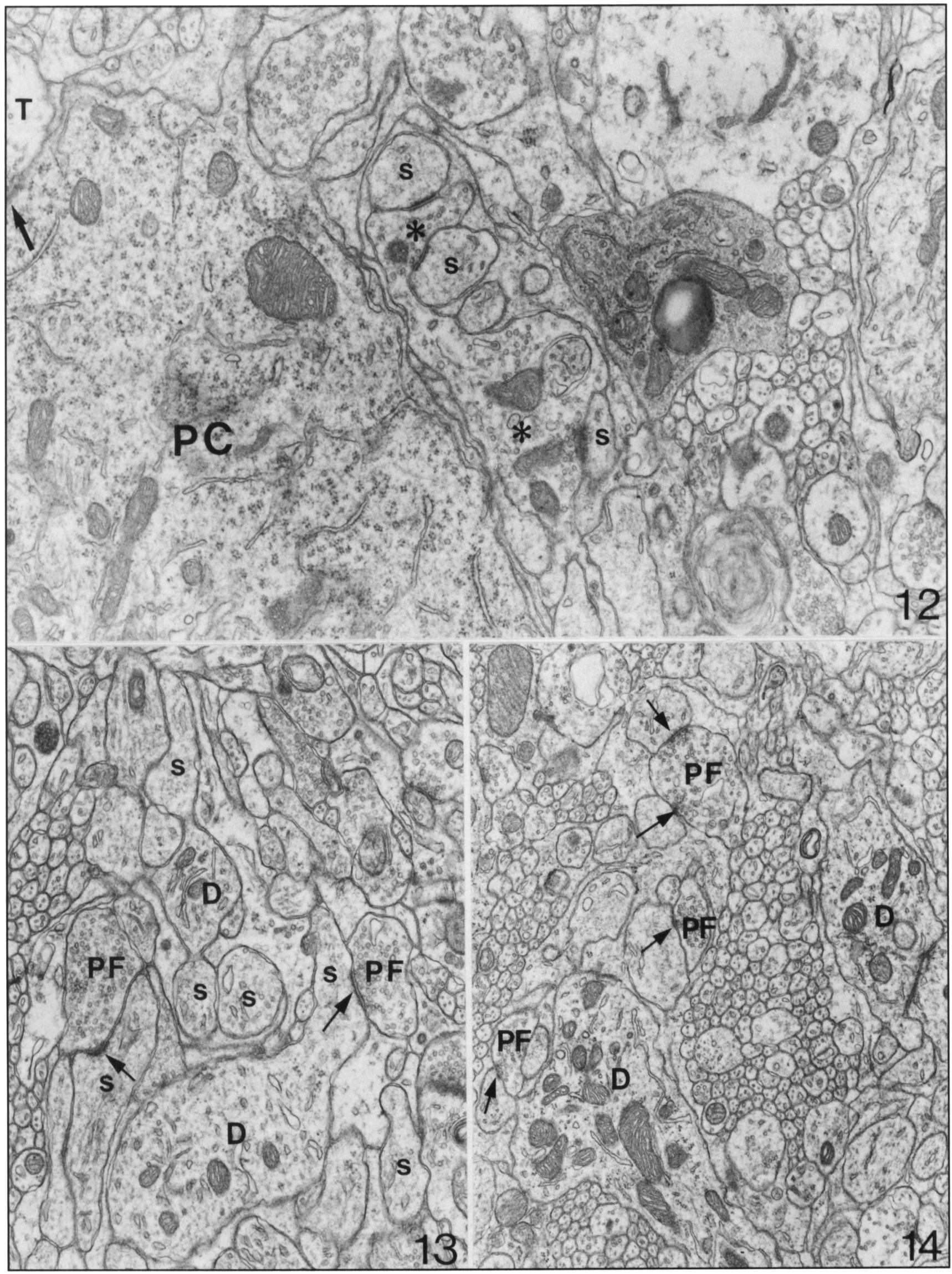


Figure 12 - Electron micrograph of a grafted Purkinje cell $(P C), 14$ days after grafting. At this age, varicosities (asterisks) from host climbing fibers still occupy a perisomatic position, and synapse on somatic spines $(s)$. The arrow points to a symmetrical synapse between an axon terminal $(T)$ of an inhibitory interneuron and the smooth surface of the grafted Purkinje cell body. $\times 35,000$

Figure 13-Electron micrograph of the neuropil of the molecular layer of a pcd cerebellum, II days after grafting. The distal dendrites of the grafted Purkinje cells $(D)$ are forming numerous spines $(s)$. Some of the latter are already synaptically contacted (arrow's) by host parallel fibers (PF). $\times 22,000$

Figure 14 - Electron micrograph of the neuropil of the molecular layer of a pcd cerebellum, 14 days after grafting. Dendritic profiles $(D)$ of the grafted Purkinje cells occupy a large area of the micrograph. Note that axonal varicosities of the parallel fibers (PF) establish numerous synapses (arrow's) on the dendritic spines, $\times 18,000$

have revealed that there is a transient phase of redundancy of connections, such that PCs are multiply innervated by climbing fibers, ${ }^{27,28}$ followed by a period of rearrangement that results in the elimination of supranumerary connections and the stabilization of the remaining ones. This transient phase lasts in the rat from 3 to 13 days postnatally. Similar studies on the grafted cerebellum ${ }^{21}$ have revealed that the same transient phase of multiple innervation is also present during the synaptogenesis between host climbing fibers and grafted PCs. The only noticeable difference is that this phase is shorter in the grafted pcd mouse (the regression is achieved in five instead of 10 days). This time difference could be related to the fact that when grafted PCs start their synaptogenic period, all presynaptic parallel fibers are already present in close vicinity to the immature PCs, and that they establish synaptic contacts earlier and faster. Indeed, the precocious appearance of numerous parallel fiber synapses on grafted PCs might explain the early regression of their multiple innervation by climbing fibers, since during normal development this regressive process is in part due to competition with parallel fibers. ${ }^{29}$ It is nevertheless remarkable that such a transient multiple innervation also exists in this experimental situation.

\section{Embryonic-Adult Cellular Interactions: New Aspect of Neural Plasticity}

The results obtained from the study of short-term survivals indicate that progenitors and young postmitotic PCs grafted in the adult pcd cerebellum are able to achieve quasi-normal development, despite the abnormal environment provided by the mutant cerebellum. What is most remarkable about these observations is that the nature of the cellular interactions and their sequential order are similar to those leading to the maturation of PCs during normal cerebellar ontogeny. Grafted PCs thus follow a predetermined pattern of maturation as if an internal clock, independent of environmental signals, regulates their developmental program.

As reported in this review, the radial invasion of grafted PCs takes place by a gliophilic mechanism of neuronal migration, which implies that the adult Bergmann fibers are able to reexpress surface molecules needed for their participation in a migratory process. The dendritic development and the synaptic investment of these grafted PCs also imply that the embryonic neurons influence, in a precise timed sequence, the sprouting of adult axons. Moreover, this orderly sprouting suggests that adult neurons can recognize the same signals regulating the specificity of the synaptogenic process recognized by immature neurons. Finally, the existence of a transient phase of climbing fibers multiply innervating grafted PCs indicates that the latter might be intrinsically encoded to induce the formation of the supranumerary synapses.

The most likely, but not necessarily unique, interpretation of the "rejuvenescent" process of neural cells of the adult host, theoretically needed for their successful interactions with grafted $\mathrm{PCs}$, is that these embryonic neurons by themselves, or by the presence of growth factors within the implant, regulate gene expression of adult neurons and glial cells. This molecular plasticity would generate a transient permissive microenvironment allowing the synaptic integration of the grafted neurons, leading to the subsequent restoration of the impaired cortical circuit of the pcd cerebellum.

\section{REFERENCES}

1. Transplantation in the Nervous System. Special Issue. Trends Neurosci 1991; $14\left(\mathrm{n}^{\circ} 8\right)$.

2. Lindvall $\mathrm{O}$, Brundin $\mathrm{P}$, Widner $\mathrm{H}$, et al. Grafts of fetal dopaminergic neurons survive and improve motor function in Parkinson's disease. Science 1990; 247: 574-577.

3. Sotelo C, Alvarado-Mallart RM. Growth and differentiation of cerebellar suspensions transplanted into the adult cerebellum of mice with heredodegenerative ataxia. Proc Natl Acad Sci USA 1986; 83: 1135-1139.

4. Sotelo C, Alvarado-Mallart RM. Reconstruction of the defective cerebellar circuitry in adult Purkinje cell degeneration mutant mice by Purkinje cell replacement through transplantation of solid embryonic grafts. Neuroscience 1987; 20: 1-22.

5. Sotelo C, Alvarado-Mallart RM. Cerebellar transplantation in adult mice with heredo-degenerative ataxia. Ann NY Acad Sci 1987; 495: 242-257.

6. Keep M, Alvarado-Mallart RM, Sotelo C. New insight on the factors orienting the axonal outgrowth of grafted Purkinje cells in the pcd cerebellum. Dev Neurosci 1992; 14: 153-165.

7. Sotelo C, Alvarado-Mallart RM. The reconstruction of cerebellar circuits. Trends Neurosci 1991; 14: 350-355.

8. Wu Ch, Bao X, Zhang Ch, et al. Fetal tissue grafts for cerebellar atrophy. Chin Med J 1991; 104: 198-203.

9. Mullen RJ, Eicher EM, Sidman RL. Purkinje cell degeneration, a new neurological mutation in the mouse. Proc Natl Acad Sci USA 1976; 73: 208-212.

10. Landis SC, Mullen RJ. The development and degeneration of Purkinje cells in pcd mutant mice. J Comp Neurol 1978; 177 : 125-144.

11. Wassef $M$, Simons J, Tappaz $M L$, et al. Non-Purkinje cell GABAergic innervation of the deep cerebellar nuclei: a quantitative immunocytochemical study in C57BL and in Purkinje cell degeneration mutant mice. Brain Res 1986; 399: 125-135.

12. Wassef M, Sotelo C, Cholley B, et al. Cerebellar mutations affecting the postnatal survival of Purkinje cells in the mouse disclose a longitudinal pattern of differentially sensitive cells. Dev Biol 1987; 124: 379-389.

13. Ghetti B, Norton J, Triarhou LC. Nerve cell atrophy and loss in the inferior olivary complex of "Purkinje cell degeneration" mutant mice. J Comp Neurol 1987; 260: 409-422. 
14. Shojaeian H, Delhaye-Bouchaud N, Mariani J. Stability of inferior olivary neurons in rodents. I. Moderate cell loss in adult Purkinje cell degeneration mutant mouse. Dev Brain Res 1988; 38: 211 218.

15. Ghetti B, Alyea CJ, Muller J. Studies on the Purkinje cell degeneration (pcd) mutant: primary pathology and transneuronal changes. J Neuropathol Exp Neurol 1987; 37: 617.

16. Holmes $\mathrm{G}$. A form of familial degeneration of the cerebellum. Brain 1907; 30: 467-489.

17. Gardette R, Alvarado-Mallart RM, Crepel F, et al. Electrophysiological demonstration of a synaptic integration of transplanted Purkinje cells into the cerebellum of the adult Purkinje cell degeneration mutant mouse. Neuroscience 1988; 24: $777-789$.

18. Changeux JP, Danchin A. Selective stabilization of developing synapses as a mechanism for specification of neuronal networks. Nature 1976; 264: 705-712.

19. Sotelo C, Alvarado-Mallart RM. Embryonic and adult neurons interact to allow Purkinje cell replacement in mutant cerebellum. Nature 1987; 327: 421-423.

20. Sotelo C, Alvarado-Mallart RM, Gardette R, et al. Fate of grafted embryonic Purkinje cells in the cerebellum of the adult "Purkinje cell degeneration" mutant mouse. I. Development of reciprocal graft-host interactions. J Comp Neurol 1990; 295: 165-187.

21. Gardette R, Crepel F, Alvarado-Mallart RM, et al. The fate of grafted embryonic Purkinje cells in the cerebellum of the adult "Purkinje cell degeneration" mutant mouse. II. Development of synaptic responses: an "in vitro" study. J Comp Neurol 1990; 295: 188196.
22. Miale IL, Sidman RL. An autoradiographic analysis of histogenesis in the mouse cerebellum. Exp Neurol 1961; 4: 277-296.

23. Ramón y Cajal S. Sur les fibres moussues et quelques points douteux de la texture de l'écorce cérébelleuse. Trab Lab Invest Biol Univ Madrid 1926; 24: 215-251.

24. Ramón y Cajal S. Histologie du Système Nerveux de l'Homme et des Vertébrés, Vol 2. Paris: Maloine 1911.

25. Larramendi LMH. Analysis of synaptogenesis in the cerebellum of the mouse. In: Llinas R, ed. Neurobiology of Cerebellar Evolution and Development. Chicago: AMA-ERF Institute for Biomedical Research 1969; 803-843.

26. Sotelo C. Purkinje cell ontogeny: formation and maintenance of spines. In: Corner MA, Baker RE, van de Poll NE, et al., eds. Maturation of the Nervous System. Prog Brain Res 1978; 48: 149-168.

27. Crepel F, Mariani J, Delhaye-Bouchaud N. Evidence for a multiple innervation of Purkinje cells by climbing fibers in the immature rat cerebellum. J Neurobiol 1976; 7: 567-578.

28. Mariani J, Changeux JP. Ontogenesis of olivocerebellar relationships. I. Studies by intracellular recordings of the multiple innervation of Purkinje cells by climbing fibers in the developing rat cerebellum. J Neurosci 1981; 1: 696-702.

29. Crepel F, Delhaye-Bouchaud N, Dupont JL. Fate of the multiple innervation of cerebellar Purkinje cells by climbing fibers in immature control, X-irradiated and hypothyroid rats. Dev Brain Res 1981; 1: 59-71. 